\begin{abstract}
Iranica
Abstracta Iranica Revue bibliographique pour le domaine irano-aryen

Volume 34-35-36 | 2017

Comptes rendus des publications de 2011-2013
\end{abstract}

\title{
David Stronach. The Territorial Limits of Ancient Media: an Architectural Perspective
}

\section{Rémy Boucharlat}

\section{(2) OpenEdition}

1 Journals

\section{Édition électronique}

URL : http://journals.openedition.org/abstractairanica/42176

DOI : 10.4000/abstractairanica.42176

ISSN : 1961-960X

Éditeur :

CNRS (UMR 7528 Mondes iraniens et indiens), Éditions de l'IFRI

Référence électronique

Rémy Boucharlat, «David Stronach. The Territorial Limits of Ancient Media: an Architectural Perspective », Abstracta Iranica [En ligne], Volume 34-35-36 | 2017, document 123, mis en ligne le 30 juillet 2017, consulté le 05 octobre 2020. URL : http://journals.openedition.org/abstractairanica/42176 ; DOI : https://doi.org/10.4000/abstractairanica.42176

Ce document a été généré automatiquement le 5 octobre 2020.

Tous droits réservés 


\title{
David Stronach. The Territorial Limits of Ancient Media: an Architectural Perspective
}

\author{
Rémy Boucharlat
}

\section{RÉFÉRENCE}

David Stronach. « The Territorial Limits of Ancient Media: an Architectural Perspective ", in: H. Baker, K. Kaniuth und A. Otto, eds., Stories of long ago. Festschrift für Michael D.

Roaf. 2012, Münster, Ugarit Verlag, p. 667-684. (AOAT 397)

Après bien d'autres archéologues, l'A. relève les fortes similarités de plan entre les "forts" du Zagros, Nush-i Jan, Godin Tépé, Tell Gubba, et plus à l'est sur le Plateau iranien, Tépé Ozbaki d'un côté et la "citadelle" d'Ulug Dépé au Turkménistan méridional à plus de $1500 \mathrm{~km}$ de distance. Le décalage chronologique, maintenant avéré, entre les deux régions, (VIII $-\mathrm{VII}^{\mathrm{e}}$ à l'ouest, premiers siècles du I ${ }^{\text {er }}$ mill. à Ulug) conduise D. Stronach, comme o. Lecomte, le fouilleur d'Ulug Dépé, à voir une influence, inattendue, d'est en ouest. Cet aspect d'une culture commune dans l'architecture estelle aussi un marqueur d'une entité ethnique, comme le suggère le titre de l'article ? Un autre trait architectural important, la salle à colonnes, utilisée dans cette même architecture " mède ", mais aussi dans l'architecture urartéenne, peut-être, posturartéenne plus sûrement, montre qu'il ne faut pas conclure trop vite. L'important décalage chronologique, problème que l'A. n'aborde pas, ferait reconnaître des Mèdes en Asie centrale deux siècles avant les premières sources écrites néo-assyriennes les mentionnant dans le Zagros. 


\section{AUTEURS}

RÉMY BOUCHARLAT

UMR 5133 CNRS-Université de Lyon 